\title{
Central Processing Unit Board Device
}

National Cancer Institute

\section{Source}

National Cancer Institute. Central Processing Unit Board Device. NCI Thesaurus. Code C49897.

The main circuit board housing the central processing unit. 